\title{
A memória da ditadura militar e seu uso como estratégia de marketing na sociedade do espetáculo
}

\section{The memory of the military dictatorship and its use as a marketing strategy in the society of the spectacle}

Cláudio Novaes Pinto Coelho ${ }^{1}$ 


\section{Resumo}

O objetivo do artigo é desenvolver reflexões que possam colaborar para a compreensão de algumas especificidades da sociedade brasileira, no que diz respeito à memória de um período marcado pela repressão estatal, e como se dá a atuação da mídia dentro desse processo. Em especial, pretende-se refletir, mediante uma abordagem histórica, sobre uma situação contemporânea, que é a utilização da memória da ditadura militar como estratégia de marketing pelo jornal Folha de S.Paulo. A base para o desenvolvimento do artigo sobre a questão da memória no período da ditadura é um diálogo com os textos de Huyssen e Sarlo. A respeito da sociedade brasileira, particularmente sobre as características da transição da ditadura militar para a "Nova República", a principal referência é Florestan Fernandes e autores que dialogam com a sua concepção.

Palavras-chave

Memória, ditadura militar, sociedade brasileira, mídia, marketing.

\section{Abstract}

This paper aims to develop reflections that can collaborate for the understanding of some specificities of Brazilian society regarding the memory of a period ruled by state repression, and how the media works within this process. In particular, this article intends to reflect, supported by a historical approach, upon a contemporary situation, which is the use of the memory of the military dictatorship as a marketing strategy by the Folha de S.Paulo newspaper. The basis for the development of the article on the question of memory during the military dictatorship period is a dialogue with texts by Huyssen and Sarlo. Regarding Brazilian society, particularly about the characteristics of the transition from the military dictatorship to the "New Republic", the main reference is Florestan Fernandes and authors that dialogue with his conception.

\section{Keywords}

Memory, military dictatorship, Brazilian society, media, marketing. 
Andreas Huyssen, em seu livro Culturas do passado-presente, chama atenção para os aspectos problemáticos da construção de uma memória nacional sobre períodos repressivos, devido a um eventual processo de cristalização de identidades e de exclusão de visões mais complexas. Por sua vez, Beatriz Sarlo, na obra Tempo passado, trabalha com a tendência, na Argentina, para o predomínio de narrativas memorialísticas marcadas pela subjetividade, argumentando que esta tendência coloca em risco a compreensão histórica do período ditatorial e a possibilidade de uma avaliação crítica de posicionamentos políticos postos em prática nesse período.

No caso da sociedade brasileira, dificilmente seria possível falarmos da construção de uma memória nacional sobre o período da ditadura militar. As iniciativas governamentais não produziram este resultado. Nenhum governante tomou a iniciativa de questionar a Lei da Anistia, que impede a punição dos crimes cometidos pelos governos ditatoriais, e as iniciativas, durante o governo de Dilma Rouseff, de criação de comissões da verdade não foram capazes de formar uma memória nacional sobre a ditadura iniciada em 1964. Ou seja, não houve nenhuma mobilização social capaz de conseguir isso.

Mas isso não significa a inexistência de produtos midiáticos sobre o período da ditadura militar. Muito pelo contrário, ainda no período da ditadura, dentro do contexto da "abertura" política que marcou o governo do General Figueiredo, na parte final da década de 1970, teve início uma proliferação de matérias jornalísticas, livros, peças de teatro, filmes e séries televisivas a respeito dessa época.

No que se refere ao contexto brasileiro, pode-se argumentar que a presença da valorização da subjetividade esteve presente desde o início da produção memorialística sobre o período, mas acompanhada por uma visão crítica, no caso, uma autocrítica, sobre as posições políticas tomadas por parcelas significativas da esquerda brasileira, principalmente, a adesão à luta armada durante o final da década de 1960 e o início da década de 1970.

A publicação de memórias de participantes da luta armada contra a ditadura militar correspondia a uma demanda de mercado, de um público interessado 
em saber o que a repressão política e a censura, que vigoraram fortemente na primeira metade da década de 1970, tinham impedido de ser divulgado. A presença significativa, no mercado jornalístico e editorial, de veículos da chamada imprensa alternativa e de editoras com posicionamentos contrários à ditadura era indicativa da relevância deste público. A publicação de livros memorialísticos, em especial no que diz respeito a Fernando Gabeira, também pode ser considerada como uma estratégia de marketing, inserida no contexto da sociedade capitalista do espetáculo.

Atualmente, o jornal Folha de S.Paulo desenvolve estratégias comunicacionais para divulgar o centenário da publicação. Faz parte das estratégias de divulgação da marca, ou seja, da imagem do jornal, a alteração do seu slogan de "Um jornal a serviço do Brasil" para "Um jornal a serviço da Democracia" e uma campanha publicitária colocando o jornal como contrário às ditaduras, afirmando que a publicação não esqueceu o período da ditadura militar, da qual teria sido uma vítima.

\section{A ausência de uma memória nacional sobre a ditadura militar}

Huyssen (2014) aponta a existência de uma cultura e de uma política da memória em diferentes regiões do mundo, situando o fim das ditaduras militares na América Latina como um dos elementos desta valorização da memória em escala mundial:

No decorrer das duas últimas décadas, a cultura da memória e a política da memória tornaram-se verdadeiramente transnacionais, se não globais. Da África do Sul à Argentina e ao Chile, da Bósnia e do Kosovo à Ruanda, o trauma histórico e as violações dos direitos humanos despontaram como loci privilegiados da comemoração pública no trabalho de arquitetos, acadêmicos, pintores e escritores. Criaram-se Comissões da Verdade e, em países como Argentina e Chile, os tribunais tornaram-se atuantes nos últimos tempos, após um período prolongado de silêncio sobre o terrorismo de Estado do período da Guerra Fria. [...]

Depois da queda do Muro de Berlim, a política global dos memoriais cristalizou-se, na década de 1990, em torno de três grandes fatores; o discurso sobre o Holocausto e debates públicos mais intensos sobre o quinquagésimo e o sexagésimo aniversários de eventos relacionados com a Segunda Guerra Mundial; as transições para a democracia, após 
o colapso dos regimes de terrorismo de Estado na América Latina e do apartheid na África do Sul; e a recorrência da limpeza étnica e do genocídio, na atualidade, nos Balcãs e em Ruanda. (HUYSSEN, 2014, p. 139)

Tanto Huyssen quanto Sarlo (2007) mencionam o papel do julgamento dos responsáveis pelo terrorismo de Estado para a construção de memórias nacionais sobre a repressão estatal. Além dos julgamentos na América Latina, Huyssen escreve sobre os julgamentos ocorridos na década de 1960 que colocaram o Holocausto, na Alemanha (dividida na época em dois países), no centro das atenções:

Mas a opinião pública da época (década de 1950) estava mais preocupada com os temores da guerra nuclear, do rearmamento alemão e do anticomunismo do que com o Holocausto.

A situação só se modificou no começo da década de 1960, quando o julgamento de Eichmann em Jerusalém ocupou o centro do palco, e quando o Julgamento de Auschwitz, em Frankfurt, detalhadamente transcrito na imprensa diária, gerou uma das maiores articulações artísticas da memória do Holocausto na Alemanha: a peça do exilado alemão Peter Weiss intitulada The Investigation (O Interrogatório), que se tornou um evento teatral definidor nas duas Alemanhas, na ocasião. (HUYSSEN, 2014, p. 128)

Por sua vez, Sarlo argumenta que a produção memorialística sobre a ditadura militar na Argentina foi fundamental para a condenação dos responsáveis pelo terrorismo de Estado:

A memória foi o dever da Argentina posterior à ditadura militar e o é na maioria dos países da América Latina. O testemunho possibilitou a condenação do terrorismo de Estado; a ideia do "nunca mais" se sustenta no fato de que sabemos a que nos referirmos quando desejamos que isso não se repita. Como instrumento jurídico e como modo de reconstrução do passado, ali onde outras fontes foram destruídas pelos responsáveis, os atos de memória foram uma peça central da transição democrática, apoiados às vezes pelo Estado e, de forma permanente, pelas organizações da sociedade. Nenhuma condenação teria sido possível se esses atos de memória, manifestados nos relatos de testemunhas e vítimas não tivessem existido. (SARLO, 2007, p. 20) 
A articulação entre julgamentos de responsáveis pelo terrorismo de Estado e a divulgação de memórias das vítimas deste terrorismo simplesmente não aconteceu no contexto brasileiro. Os julgamentos foram preventivamente evitados pela Lei da Anistia, promulgada ainda no período da ditadura militar, e as memórias começaram a ser publicadas a partir da Anistia.

A garantia futura da impunidade presente na Lei da Anistia, de agosto de 1979, e posteriormente incorporada à Constituição de 1988, estava configurada pelos "crimes conexos"; ou seja, conforme o parágrafo primeiro da Lei, estariam anistiados crimes de qualquer natureza relacionados com crimes políticos. Sendo assim, crimes como a prática da tortura e assassinatos estavam previamente perdoados, antes que pudessem acontecer denúncias e julgamentos. Nas palavras de Maria Helena Moreira Alves, no livro Estado e oposição no Brasil (1964-1984), a Lei da Anistia significou:

um perdão incondicional aos integrantes do Aparato Repressivo que estiveram envolvidos com a tortura. $O$ dispositivo era uma evidente vitória dos setores de linha-dura, e eliminava a possibilidade de denúncia criminal contra os acusados de tortura. Ele dificultaria eventuais investigações sobre as atividades do Aparato Repressivo, constituindo portanto uma derrota para a oposição. (MOREIRA ALVES, 1987, p. 268)

A derrota das forças de oposição à ditadura, incapazes de garantir a possibilidade de julgamentos e punições dos responsáveis pelo terrorismo de Estado, não foi revertida. A incorporação dos dispositivos da Lei da Anistia nas disposições transitórias da Constituição de 1988 é uma evidência disso. O aparato repressivo criado durante a ditadura militar não foi posteriormente desmontado, e a Constituição de 1988 manteve os militares na sua condição de responsáveis pela manutenção da "ordem social". De acordo com Zaverucha:

O artigo 142 diz que as Forças Armadas "destinam-se à defesa da pátria, à garantia dos poderes constitucionais e, por iniciativa de qualquer destes, da lei e da ordem". Mas, logicamente, como é possível se submeter e garantir algo simultaneamente? 
Lógica à parte, são os militares quem têm o poder constitucional de garantir o funcionamento do Executivo, Legislativo e Judiciário, a lei e a ordem quando deveria ser o reverso. Ou seja, as Forças Armadas são baluartes da lei e da ordem definidas por elas mesmas, não importando a opinião do presidente da República ou do Congresso Nacional. Portanto, cabe às Forças Armadas o poder soberano e constitucional de suspender a validade do ordenamento jurídico, colocando-se legalmente fora da lei.

[...] Ora, se os militares são garantes, terminam sendo, também, organizadores da vida política. As Forças Armadas deixam de ser meios para se transformar, quando necessário, em fim do Estado. (ZAVERUCHA, 2010, p. 48)

No contexto brasileiro, a transição para um regime político formalmente democrático e um Estado de Direito se deu de modo limitado e não significou uma ruptura efetiva com os aspectos fundamentais do período anterior. Pode-se afirmar que a "transição democrática" foi um processo que, em linhas gerais, não saiu do controle dos militares. Por exemplo, o "término" da ditadura ocorreu dentro dos mecanismos eleitorais criados por ela própria, após a derrota da emenda constitucional pelo retorno das eleições diretas para a Presidência da República, com a eleição do Presidente por um colégio eleitoral formado por parlamentares e não diretamente pela população.

Florestan Fernandes avaliou, do seguinte modo, a derrota da campanha pelas eleições diretas:

Mais que a eleição direta de um presidente, perdeu-se a oportunidade histórica única de usar o rancor contra a ditadura e a consciência geral da necessidade de mudar profundamente como o ponto de partida de uma transformação estrutural da sociedade civil e do Estado. E se ganhou uma mistificação monstruosa: a montagem política e ideológica de um Frankenstein, batizado Nova República e trombeteado pela cultura da comunicação de massa como "uma vitória do Povo na luta pela democracia"! (FERNANDES, 1986, p. 28)

Em um texto em que dialoga com a visão de Florestan Fernandes sobre a sociedade brasileira, David Maciel chama atenção para a combinação (o Frankenstein ao qual se refere Florestan Fernandes) de elementos democráticos e ditatoriais na Constituição de 1988 e no regime político posterior à ditadura militar: 
O resultado foi uma Constituição que estabeleceu uma institucionalidade democrática devidamente contraditada pelos elementos da institucionalidade autoritária que sobreviveram, legalizando e consumando o processo de reforma da autocracia burguesa, em curso desde o início da transição lenta, gradual e segura, e definindo um Estado sincrético, no qual os elementos políticos democráticos combinam-se com os elementos oligárquicos e mesmo fascistas de modo altamente funcional para a preservação da ordem social burguesa, principalmente numa situação de crise de hegemonia. (MACIEL, 2014, p. 299-300)

Um dos principais aspectos da manutenção do aparato repressivo da ditadura, que caracteriza o Estado sincrético brasileiro, é a preservação do papel das polícias militares:

A partir, principalmente, de 1969, auge da repressão política, houve uma reversão nas funções das polícias. As Polícias Militares saíram do seu aquartelamento e foram lançadas nas ruas com o objetivo de fazer o papel do policiamento ostensivo e manutenção da ordem pública, aí incluindo o controle e o tráfego de veículos. Foi retirada a prerrogativa jurisdicional do delegado de polícia para realizar a instrução dos processos sumários. [...]

A Constituição de 1988 nada fez para devolver à Polícia Civil algumas de suas atribuições existentes antes do início do regime militar. A Polícia Civil é uma das instituições que mais perdeu poder com o advento do regime militar. (ZAVERUCHA, 2010, p. 56-57)

A atuação da polícia militar significa a manutenção da militarização da vida cotidiana implantada pela ditadura. Trata-se da sobrevivência de um dos principais elementos do "fascismo cotidiano", para usar a expressão de Nelson Werneck Sodré (1990), ou seja, da presença, no dia a dia, de um dos componentes principais do terrorismo de Estado, que se volta principalmente contra as classes populares, em especial, os jovens e negros. É um desdobramento da visão, presente na Constituição de 1988, que atribui aos militares a garantia da defesa da "ordem" e das instituições. 


\section{Memórias da ditadura no Brasil: política e sociedade do espetáculo}

Huyssen mostra os vínculos, na Argentina, entre a memória da ditadura, os julgamentos dos militares e o combate ao terrorismo de Estado, argumentando que, nesse país, foi possível uma transição para a democracia que tem sido capaz de manter os militares afastados da vida política:

A memória da ditadura foi crucial para o sucesso da transição para a democracia na Argentina. Podemos dizer que na Argentina de hoje, apesar de suas dificuldades econômicas, tem os mais intensos debates internos sobre a memória entre os países latino-americanos que foram atormentados pelas campanhas militares de repressão, tortura e assassinato nas décadas de Guerra Fria posteriores aos anos 1960 - mais intensos que os do Brasil, Uruguai, Chile ou Guatemala. Esse "sucesso" certamente foi um dos fatores que mantiveram os militares nos quartéis durante a queda livre econômica e social do país desde 2001. (HUYSSEN, 2014, p. 161)

O afastamento dos militares da política, no contexto brasileiro, manteve-se, conforme os mecanismos da sociedade do espetáculo, apenas como uma aparência, com a imagem de uma superação do período da ditadura e de uma democracia consolidada, trazida pelo imaginário da "Nova República". Essa aparência de afastamento dos militares da política evidentemente não existe mais, após a ascensão ao poder, na sequência do impeachment/golpe de 2016, do atual presidente: um militar reformado, vinculado à extrema direita do exército (linha-dura), e que trouxe para o seu governo uma grande quantidade de militares em postos-chave.

Como já havia sido antecipado por David Maciel (2014), os elementos oligárquicos e fascistas presentes no Estado sincrético brasileiro podem ser acionados em caso de crise hegemônica. Como a crise da "Nova República", evidenciada a partir das manifestações de junho de 2013, que ainda está em vigor.

Em uma linha argumentativa muito próxima da visão de Sarlo, Huyssen entende que houve um preço a se pagar, em termos do que é lembrado e do que é esquecido, para o "sucesso" da Argentina: o estabelecimento de uma clara distinção entre algozes e vítimas, o que dependeu do esquecimento da dimensão política da atuação das vítimas na ditadura: 
No nível narrativo, o relatório Nunca Más estabeleceu a figura do desaparecido como uma vítima inocente do terrorismo de Estado. Essa estratégia "esqueceu" a dimensão política da insurgência esquerdista que a ditadura militar vinha tentando extirpar. Esse esquecimento foi necessário, na época, por duas razões: primeiro, foi necessário para invalidar os argumentos apresentados pela defesa dos generais, que se baseava na ideia de que o golpe e a repressão tinham sido causados pelo terrorismo armado da esquerda radical - os Montoneros e o Exército Revolucionário do Povo (ERP). Segundo, e mais importante, foi necessário para permitir que toda a sociedade argentina, inclusive os não participantes e os beneficiários da própria ditadura, se congregassem em torno de um novo consenso nacional: a separação clara entre criminosos e vítimas, culpados e inocentes. (HUYSSEN, 2014, p. 162-163)

No Brasil, onde não existe memória nacional sobre o período da ditadura militar, não há consenso sobre a separação entre criminosos e vítimas. Ao contrário da Argentina, onde o documento Nunca Más é um relatório oficial, aqui, os primeiros relatórios sobre a repressão estatal, divulgados na década de 1980, também intitulados Nunca Mais, foram fruto da sociedade civil, de organizações vinculadas a denominações religiosas. Os relatórios das comissões da verdade, décadas após os relatórios do projeto Brasil: nunca mais, não desempenharam o mesmo papel do relatório argentino. Na Argentina, a memória produzida conseguiu desconstruir o discurso dos militares a respeito de dois campos (extrema-direita versus extrema-esquerda) em confronto como justificativa da repressão; o mesmo não aconteceu no Brasil, onde permanece a disputa simbólica/ideológica sobre quem é criminoso e quem é vítima. Quanto à Argentina, assim escreveu Huyssen:

Tomados em conjunto, o relatório Nunca Más e o julgamento deslegitimaram a justificativa retroativa do golpe contida na teoria de "los dos demonios" (os dois demônios), que tivera certa aceitação durante os anos do governo Alfonsín, logo após 1983. Os dois demônios seriam os grupos terroristas da direita radical e o terrorismo da guerrilha urbana de esquerda, numericamente insignificante, que nunca somou mais de seiscentos a oitocentos combatentes no país inteiro. Ambos eram tidos como igualmente responsáveis por desencadear o golpe militar. (HUYSSEN, 2014, p. 162)

Se, na Argentina, conforme argumentam Huyssen e Sarlo, o esquecimento da dimensão política da atuação das vítimas do terrorismo de Estado foi necessário 
para o julgamento e punição dos responsáveis por ele; no contexto brasileiro, onde a Lei da Anistia impediu o julgamento e a punição dos repressores, as memórias que começaram a ser divulgadas posteriormente à anistia se voltaram para a atuação política de vítimas da ditadura, com destaque para os que participaram da luta armada.

Em suas reflexões sobre o desenvolvimento de uma cultura da memória nas sociedades contemporâneas, Huyssen menciona a possibilidade de uma transformação da memória em mercadoria: "Na verdade, a própria memória pode tornar-se uma mercadoria a ser colocada em circulação por uma indústria voraz da cultura, sempre em busca de novos floreados" (HUYSSEN, 2014, p. 139).

Na conjuntura brasileira, houve uma combinação entre a dimensão política das memórias de vítimas da ditadura e a transformação da memória em mercadoria. O principal exemplo disso foi a publicação dos livros de memórias escritos pelo jornalista Fernando Gabeira, que participou da luta armada contra a ditadura militar, em especial do sequestro do embaixador americano no Brasil, que foi solto posteriormente em uma troca por presos políticos. Como se pode ler no livro Os movimentos libertários em questão:

Gabeira foi o primeiro participante da luta armada a romper a barreira do silêncio, revelando os pormenores da sua participação no sequestro do embaixador americano e da repressão policial-militar, em entrevista concedida ainda no exílio a O Pasquim n.490 (17-23/11/78). A apresentação do texto, escrita pelo cartunista Ziraldo, dizia o seguinte:

"A entrevista mais emocionante de que participei no 'Pasquim'. Uma entrevista que eu gostaria que todos os brasileiros lessem. Todos. Meus filhos, principalmente".

Foi desse modo, já então bombástico, que Gabeira foi apresentado à opinião pública brasileira. (COELHO, 1987, p. 36)

Não por acaso, os livros de memórias escritos por Gabeira, O que é isso, companheiro?, sobre a sua participação na luta armada e O Crepúsculo do macho, sobre o exílio, foram publicados pela editora Codecri, vinculada ao O Pasquim, 
o principal jornal da chamada imprensa alternativa; ou seja, publicações que não faziam parte dos grandes grupos midiáticos e que, de modo geral, se posicionavam contrárias à ditadura militar. A estratégia de marketing em torno de Fernando Gabeira, a construção da sua imagem como o portador de uma experiência que precisava ser conhecida por todos pode ser considerada um sucesso. Apenas a título de exemplo, conforme a edição da Folha de S.Paulo publicada em 3 de outubro de 1982, entre 1979 e 1982, haviam sido vendidos cerca de 400 mil exemplares dos seus livros.

A repercussão das obras de Gabeira foi tão grande, em especial do primeiro livro, que rapidamente a sua imagem deixou de circular apenas em veículos alternativos e passou a fazer parte de produtos midiáticos da indústria cultural brasileira. Em um disco lançado em 1980, a cantora Rita Lee incluiu em uma canção escrita por ela, Orra $M e u$, os seguintes versos como refrão da música: "Guerrilheiro/Forasteiro/Orra Meu", em uma clara referência à trajetória de vida de Gabeira e ao título de seu livro. A expressão "orra meu" pode ser considerada a versão paulistana da expressão "o que é isso, companheiro?". O disco, intitulado Rita Lee, foi lançado pela gravadora Som Livre, uma empresa do Grupo Globo, a principal corporação da indústria cultural no Brasil. Em 1997, ocorreu o lançamento de $O$ Que é isso, Companheiro?, filme dirigido por Bruno Barreto, com um elenco recheado de atores e atrizes vinculados à Globo. O filme concorreu como candidato ao Oscar de melhor filme estrangeiro, mas não venceu.

\section{Memória e história: a relação passado/presente}

Beatriz Sarlo, no livro Tempo passado, estabelece um contraponto entre as produções memorialísticas e as pesquisas históricas acadêmicas. Tendo em vista que, segundo a autora, estaríamos vivendo um momento em que a presença da subjetividade é considerada indispensável para a produção de narrativas tidas como verdadeiras, as narrativas memorialísticas estariam sendo valorizadas, em detrimento de um conhecimento histórico produzido de acordo com os cânones da pesquisa científica. As produções memorialísticas tenderiam a construir explicações 
totalizantes, fechadas nelas mesmas, e que resistiriam a serem criticadas; enquanto os trabalhos historiográficos seriam capazes de construir explicações complexas e que deixariam margem para novas investigações. De acordo com Sarlo,

\begin{abstract}
Quando uma narração memorialística concorre com a história e apoia sua exigência nos privilégios de uma subjetividade que seria sua garantia (como se pudéssemos voltar a crer em alguém que simplesmente diz: "Falo a verdade do que aconteceu comigo ou do que vi que acontecia com meu amigo, meu irmão"), ela se coloca, pelo exercício de uma imaginária autenticidade testemunhal, numa espécie de limbo interpretativo. (SARLO, 2007, p. 67-68)
\end{abstract}

Sem dúvida, é problemática uma identificação reducionista entre memória e história; no entanto, também é problemático o não reconhecimento da possibilidade de produções memorialísticas contribuírem para o conhecimento histórico. A existência dessa possibilidade dependeria da maneira como a relação entre passado e presente aparece na narrativa memorialística, e como a subjetividade ali se manifesta.

No que diz respeito ao primeiro livro de memórias de Fernando Gabeira, e de boa parte das narrativas memorialísticas publicadas no período imediatamente posterior à Lei da Anistia, não aconteceu, como na Argentina, a produção de narrativas cujo objetivo central (relacionado com o presente) era agir para garantir a punição dos principais responsáveis pelo terrorismo de Estado. No Brasil, os repressores foram anistiados preventivamente, tendo acontecido uma produção de narrativas, como os livros publicados por Alfredo Sirkis, Alex Polari e Herbert Daniel, em que os autores desenvolviam uma autocrítica (no presente) das decisões políticas tomadas no passado, isto é, a participação na luta armada contra a ditadura.

Devido à postura autocrítica, a distância entre o eu do presente e o eu do passado era assumida explicitamente, não ocorrendo uma redução da compreensão histórica à dimensão da subjetividade, pois a narrativa do passado tinha como propósito entender os motivos da adesão à luta armada, o que significa que se levava em consideração as articulações entre a experiência individual e a realidade objetiva social e histórica mais abrangente. 
A busca de Gabeira pela compreensão das suas ações passadas está presente no título, o que é isso, companheiro?, e desde o início do seu livro, quando há o relato da tentativa de asilo na embaixada da Argentina no Chile, localizada em uma rua chamada Irrazabal, após o golpe de Estado de Pinochet. Assim como muitos outros militantes da esquerda brasileira, ele viveu no Chile durante o governo socialista de Salvador Allende:

Este é um livro de um homem correndo da polícia, tentando entender como é que se meteu, de repente, no meio da Irrazabal, se há apenas cinco anos atrás estava correndo da Ouvidor para a Rio Branco, num dos grupos que faziam mais uma demonstração contra a Ditadura Militar que tomara o poder em 64. Onde é mesmo que estávamos, quando tudo começou? (GABEIRA, 1979, p. 10)

A presença, no livro, de uma visão sobre o passado que vai além da experiência individual está relacionada ao papel desempenhado pela autocrítica, que não é um posicionamento meramente pessoal, mas está associada à vivência de um ideário coletivo, exposto enquanto tal: o ideário das correntes da esquerda brasileira que aderiram à luta armada. Ideário que o livro expõe e ao mesmo tempo critica. A crítica incorpora os debates da esquerda nos anos 1970 no Brasil e fora dele, nas comunidades de exilados, sobre a experiência da luta armada. A obra exerce a autocrítica que problematiza a não adesão da população às práticas guerrilheiras, questionando a visão "vanguardista" que teria estimulado estas práticas:

Teoriza-se aí a grande ilusão do período: a luta contra o governo poderia ser feita independente do povo, por alguns grupos armados, dotados de muita técnica, e, naturalmente de ousadia. Tudo se passava como se houvesse especialistas que iam cuidar de tudo e, num determinado momento, quando não se sentissem mais ameaçados, chamariam o povo para participar daquelas lutas. (GABEIRA, 1979, p. 45)

Se há uma articulação entre produção memorialística e conhecimento histórico no livro de Gabeira, o mesmo não pode ser dito do filme que, duas décadas depois, foi produzido com base no livro, com roteiro escrito por Leopoldo 
Serran. O livro é um produto midiático de uma editora alternativa vinculada a um jornal da imprensa não corporativa. O fato de ser uma mercadoria inserida nas características da sociedade do espetáculo não inviabilizou sua condição de um bem cultural que contribuía para a compreensão histórica da sociedade brasileira, ao mesmo tempo em que narrava a experiência de vida de um indivíduo. O filme é um produto da indústria cultural, financiado pelo principal produtor cinematográfico brasileiro, Luiz Carlos Barreto, dirigido pelo seu filho, Bruno Barreto, e com distribuição nos Estados Unidos pela Miramax, uma das principais corporações cinematográficas daquele período (década de 1990). O foco do filme não é mais a trajetória de militância na esquerda brasileira de Fernando Gabeira, mas apenas um episódio desta militância, o sequestro do embaixador norte-americano, que é um dos personagens centrais da produção e é retratado de maneira extremamente simpática, como uma vítima dos guerrilheiros, em especial, do personagem Jonas. Este personagem, retratado no filme como um vilão, foi inspirado em Virgílio Gomes da Silva, um militante político que participou do sequestro do embaixador norte-americano e foi violentamente torturado e assassinado após ter sido preso durante a ditadura.

O que caracteriza a versão audiovisual de $O$ que é isso, companheiro? não é uma autocrítica do passado, feita por alguém que questiona mas não renega este passado, mas uma redefinição de quem era vítima e quem era criminoso no período da ditadura militar; indicando claramente a ausência de um consenso nacional a esse respeito e o afastamento, quando estamos diante de um produto midiático da indústria cultural, da possibilidade de combinação entre memória e história.

Este afastamento entre memória e história, no que concerne à indústria cultural, pode ser constatado ainda nos dias de hoje, como se pode perceber pela campanha publicitária desenvolvida em 2020 pelo jornal Folha de S.Paulo, uma estratégia de marketing para justificar e divulgar o novo slogan do jornal: "Um Jornal a Serviço da Democracia". A campanha teve início na edição do dia 28 de junho de 2020, lançada em editorial publicado na primeira página do jornal, que se inicia com a seguinte frase: "É sólido o edifício da jovem democracia 
brasileira", indicando a ausência de uma problematização do regime político vigente após 1985, nem sequer da situação política do país após o impeachment/ golpe de 2016, que teve o apoio do jornal. O editorial reconhece o amparo dado à ditadura, atribuindo-o à condição de erro, para em seguida celebrar o papel que a publicação teria desempenhado em defesa da democracia:

A censura calava a imprensa, que apoiou o novo regime num primeiro momento, caso desta Folha, que errou. Este jornal viu-se rapidamente engalfinhado pelo novo sistema de poder, perdendo a capacidade de reagir antes mesmo de percebê-lo.

Só na década seguinte achou meios de empreender um combate, mesmo que velado e sutil, à ditadura. E, nos anos 1980, liderou na imprensa o movimento das Diretas Já, firmando-se como defensor intransigente da democracia e das liberdades individuais. (FOLHA DE S.PAULO, 28 jun. 2020, p. A1)

O reconhecimento de que o jornal apoiou a ditadura e de que isso foi um erro não pode ser considerado sequer como a aparência de uma autocrítica, pois em nenhum momento do caderno especial, publicado nesta edição de 28 de junho de 2020, intitulado "O que foi a Ditadura", há uma descrição sobre como teria sido o apoio do jornal, que formas ele assumiu, muito menos uma análise crítica dos motivos que o teriam levado a agir como agiu. Em uma matéria, publicada no caderno, sobre a censura e a repressão às manifestações culturais, o jornal é colocado como vítima de uma intervenção da ditadura, que exigiu a demissão do jornalista Cláudio Abramo do cargo de editor do jornal. Por sua vez, a peça publicitária faz as seguintes afirmações:

A atual democracia brasileira tem 35 anos. Mais da metade dos eleitores tem menos de 40 anos. E a Folha vai fazer 100 anos. Por isso, nós vimos e nunca esqueceremos os horrores da ditadura. E sempre defenderemos a democracia. (FOLHA DE S.PAULO, 28 jun. 2020, p. A9)

O texto assume explicitamente o papel de ator político que a publicação desempenha. O jornal afirma que vai narrar para o eleitorado brasileiro, na condição de testemunha, a memória da ditadura, em nome da defesa da democracia, 
postura que seria permanente. No entanto, bastaria uma rápida olhada em uma peça publicitária de uma outra instituição que, no mesmo período do início da campanha da Folha de S.Paulo, também resolveu falar sobre a época da ditadura militar, para que aspectos fundamentais dos horrores da ditadura esquecidos pela Folha fossem lembrados: a colaboração dada pelo jornal para a tentativa de transformar em "líder popular" o General que ocupou a presidência no período em que o terrorismo de Estado foi mais violento.

Na edição de 21 de junho de 2020, os leitores da Folha de S.Paulo entraram em contato com um "informe publicitário" colocado antes da primeira página; tratava-se de uma reprodução da primeira página do jornal do dia 22 de junho de 1970, dia posterior à vitória da seleção brasileira de futebol no jogo final da copa do mundo disputada no México. Uma iniciativa da Confederação Brasileira de Futebol (CBF) como homenagem "à equipe tricampeã de 1970". A manchete do jornal foi "Eles voltam amanhã com a Taça", mas a segunda manchete dizia "Médici participa do entusiasmo do povo". O texto publicado na primeira página comentava que "Em nome de todos os brasileiros, o presidente Médici será o primeiro a homenagear o grande feito dos nossos heróis e Ihes oferecer um almoço no Palácio do Planalto". A matéria também afirmava que o presidente acertou o placar do jogo. Praticamente todo o conteúdo, que ocupa uma coluna da página, foi preenchido por declarações de Médici. O espaço restante foi ocupado por fotos dos jogadores e de lances do jogo.

Mas, em termos de colaboração do jornal com os horrores da ditadura, nada se compara com a atuação do jornal Folha da Tarde, publicação do mesmo conglomerado midiático proprietário da Folha de S.Paulo. De acordo com informações presentes no livro Cães de guarda: jornalistas e censores, do AI-5 à Constituição de 1988, de Beatriz Kushnir (originalmente uma tese de doutorado em História), no período de 1969 a 1984, os jornalistas da Folha da Tarde possuíam vínculos com os órgãos de repressão, e o jornal agia como um porta-voz não oficial do aparato repressivo da ditadura, divulgando versões (hoje diríamos "fake news") sobre a morte de presos políticos, devido às torturas, que eram do interesse 
dos torturadores. Assassinatos cometido no interior dos órgãos encarregados da repressão política eram divulgados pelo jornal como morte após tentativa de fuga ou durante tiroteio.

Ainda de acordo com o que se pode ler em Cães de guarda, o grupo empresarial proprietário da Folha de S. Paulo e de outras publicações foi acusado por militantes políticos de emprestar veículos para operações policiais, que resultaram em prisões de militantes, e por esse motivo alguns veículos do grupo foram alvo de atentados por organizações da luta armada.

A produção memorialística da Folha de S.Paulo sobre a ditadura militar confirma a interpretação de Beatriz Sarlo sobre a oposição entre memória e história. Na sua condição de um produto midiático da indústria cultural, inserido no contexto da sociedade do espetáculo, o jornal utiliza o passado da ditadura militar como um elemento da construção da imagem da publicação que corresponde aos seus interesses no tempo presente: no caso, a produção da imagem do jornal como uma publicação que não esquece da ditadura e defende sempre a democracia. Tudo o que não condiz com essa imagem é convenientemente esquecido, mas pode ser encontrado em livros sobre a história do período, em especial, sobre a atuação da imprensa.

\section{Considerações finais}

Tendo em vista a atual situação vivida pela sociedade brasileira, quando temos um governante com posições políticas de extrema-direita, que ameaça constantemente suprimir o que ainda resta de elementos de um Estado de Direito, e ataca permanentemente as instituições da democracia representativa, sem dúvida a defesa da democracia por um representante da mídia corporativa e sua afirmação de que não esquece os horrores da ditadura militar possui aspectos positivos.

No entanto, esses posicionamentos assumidos pela Folha de S.Paulo estão vinculados a uma estratégia de marketing, fazem parte de uma campanha publicitária do jornal, e não podem ser vistos como uma contribuição efetiva para a defesa da democracia, já que não questionam os limites do regime político 
estabelecido pela chamada "Nova República" e tampouco, o papel desempenhado pelo impeachment/golpe de Dilma Roussef, apoiado pela publicação e pela mídia corporativa de modo geral.

Nem sequer a afirmação de que o jornal não esquece os horrores vividos durante a ditadura militar pode ser considerada uma contribuição real para o conhecimento histórico desse período, já que a publicação não faz uma autocrítica da sua atuação durante a ditadura, não indo além de um reconhecimento superficial de que erros foram cometidos.

De modo diferente do que aconteceu na Argentina e na Alemanha, situações analisadas por Huyssen e Sarlo, no Brasil não houve uma articulação entre os julgamentos de responsáveis pelo terror de Estado e a construção de uma memória nacional sobre os períodos ditatoriais. Como, aqui, não se deu a formação de uma memória nacional, não é possível fazer uma reflexão sobre os seus eventuais aspectos problemáticos, em termos de uma visão unilateral, que não leva em consideração todas as dimensões do passado, conforme defende Huyssen.

No Brasil, a Lei da Anistia absolveu preventivamente os responsáveis pelo terror de Estado, e vivemos, desde o período ditatorial, uma disputa simbólica/ ideológica sobre quem deve ser considerado vítima e quem deve ser considerado culpado pelos acontecimentos daquele tempo. Os episódios relacionados à luta armada contra a ditadura militar foram o tema principal das primeiras produções memorialísticas e continuam a atrair atenção ainda hoje, o que dá força à narrativa mentirosa, sustentada por quem defende a ditadura militar, de que apenas os que participaram da luta armada foram alvo da repressão.

Enquanto não houver uma consciência coletiva crítica sobre o "fascismo cotidiano" estabelecido pela ditadura militar, e sobre os seus elementos que persistiram mesmo após a chamada redemocratização, viveremos sempre sob a ameaça de que eles possam servir de base para o retorno de um regime político ditatorial marcado pelo terrorismo de Estado. Produções memorialísticas capazes de colaborar para a compreensão histórica do período da ditadura militar são 
indispensáveis para que essa consciência possa se desenvolver. Mas, para que isso aconteça, essas produções não podem estar a serviço de estratégias de marketing de corporações midiáticas que agem dentro do contexto da sociedade do espetáculo e procuram construir uma imagem dessas corporações que não corresponde à realidade histórica.

\section{Referências}

SARLO, B. Tempo passado: cultura da memória e guinada subjetiva. São Paulo: Companhia das Letras, 2007.

COELHO, C. N. P. Os movimentos libertários em questão: a política e a cultura nas memórias de Fernando Gabeira. Petrópolis: Vozes, 1987.

FERNANDES, F. Nova República? Rio de Janeiro: Jorge Zahar, 1986.

GABEIRA, F. O que é isso, companheiro? Rio de Janeiro: Codecri, 1979.

HUYSSEN, A. Culturas do passado-presente: modernismo, artes visuais, políticas da memória. Rio de Janeiro: Contraponto, 2014.

KUSHNIR, B. Cães de guarda: jornalistas e censores, do AI-5 à Constituição de 1988. São Paulo: Boitempo, 2004.

MACIEL, D. A aliança democrática e a transição política no Brasil. In: PINHEIRO, M. (org.). Ditadura: o que resta da transição. São Paulo: Boitempo, 2014. p. 269-302.

MOREIRA ALVES, M. H. Estado e oposição no Brasil (1974-1984). 4. ed. Petrópolis: Vozes, 1987. 
SODRÉ, N. W. O fascismo cotidiano. Belo Horizonte: Oficina de Livros, 1990.

ZAVERUCHA, J. Relações civis-militares: o legado autoritário da Constituição de 1988. In: TELES E.; SAFATLE, V. (org.). O que resta da ditadura: a exceção brasileira. São Paulo: Boitempo, 2010. p. 41-76.

submetido em: 23 mar. 2021 | aprovado em: 13 abr. 2021 